\title{
Ethical and legal issues in
}

\section{end-of-life care}

Andrew Thorns, consultant and honorary senior lecturer in palliative medicine, Pilgrims Hospices, East Kent NHS Foundation University Trust, University of Kent, Margate

Doctors are all too often under the public spotlight for the ethical and legal dilemmas they face in end-of-life care. The demands on the doctor (Table 1) are to:

- $\quad$ keep up-to-date with changes in legislation

- $\quad$ steer the best moral path through the political rhetoric

- develop the skills necessary to manage these situations effectively.

This article will examine the common end-of-life dilemmas, although its scope does not extend to assisted dying.

\section{Approaches to decision making at the end of life}

\section{Principles and decision-making framework}

A person's right to self determination is the starting point to many ethical dilemmas. Respecting autonomy has limits, brought into focus by the Mental Capacity Act $2005^{1}$ and the increased emphasis on patient choice. The doctor needs to recognise these limits, being mindful of the other responsibilities: to benefit and not harm the patient, and to use resources justly.

\section{Truth telling}

Truth telling is fundamental to respecting autonomy. Most patients wish to have full information, although this may decrease as they approach the end of their lives. ${ }^{2,3} \mathrm{~A}$ doctor should have the skills to identify the patient's preferences and give the information honestly yet sensitively. Paternalistic withholding of a life-threatening diagnosis from a patient has no place in current healthcare, unless this is the patient's informed preference or they lack capacity to understand and use the information.

Prognosis, potential complications and future progression of disease will often remain uncertain. The clinician cannot provide clarity for all these issues but, through discussion with the patient and their families, can work with them to manage these uncertainties.

\section{Respect for autonomy and choice}

Respecting autonomy does not equate to choice. To ask 'Would you like to die at home?' offers choice. To explain all the implications of such a decision, ensuring the patient has capacity and has appreciated all the important consequences, demonstrates respect for autonomy. ${ }^{4}$ The doctor has a responsibility to ensure decisions are based on autonomous action, requiring full information, freedom from coercion and with the necessary capacity rather than simple choice. With choice being such a popular drive behind healthcare policy today, this distinction is key in end-of-life decision making.

\section{Specific challenges in end-of-life care}

\section{Withholding and withdrawing treatment}

Ethical dilemmas approaching the end of life commonly revolve around decisions to withhold or withdraw interventions or treatment. ${ }^{5}$ When the patient and doctor agree there is no benefit in carrying on or starting a new intervention the right action is clear, though skill is required on the doctor's part to manage these discussions sensitively.

Respecting the autonomy of a patient who is requesting to continue or initiate a treatment needs to be challenged when it would result in overwhelming harm, an unnecessary and unequal distribution of resources or an action that requires the doctor to act against a professional code or the law. The legal position is clear that a patient cannot demand a treatment that is not in their best interests and that doctors need not strive to preserve life at all costs. However, when there is doubt the presumption must be in favour of preserving life. .,7 $^{6}$

The doctor may be justified in withholding or withdrawing an intervention which as a result allows death to occur in the following situations:

- it is the patient's autonomous decision to withhold consent for a lifesaving intervention

- the harms of a treatment outweigh any potential lengthening of life

- the potential treatment is 'futile' - it will not achieve its specified aim (although, strictly speaking, a truly futile treatment would not, by definition, influence outcomes).

Ethical approach to such decisions. All doctors should be able to describe an ethical approach to decisions to withhold or withdraw therapy that takes into consideration the law, guidance from

\section{Table 1. Skills required of a doctor in end-of-life decision making.}

- Experience of the condition, with clear knowledge of the future progression and complications, and an ability (as best as possible) to be able to predict prognosis

- Understanding of the social situation

- Ability to consider not just the physical considerations but also the psychological, social and spiritual elements

- Up-to-date knowledge of the research evidence to apply in the given circumstances

- An ethical framework to guide complex decision making

- Ability to apply decision making to the patient's stage of disease (eg a patient in the last few days of life has different considerations to one with a number of months to live)

- Referring to, and consulting with, colleagues 
official bodies, the evidence base and the resources available. They must be aware of the patient, their capacity, beliefs and preferences as well as their clinical condition and outlook. The doctor must then formulate clearly the ethical question being asked, ensuring that their own perspective is not influencing the way it is put. This enables the options available to be established, including the moral justifications and practical solutions (Table 2). Skills in communication and coordination are required to put this into practice. This approach will now be applied to common end-of-life decisions.

\section{Clinically assisted nutrition and hydration}

The provision of hydration and nutrition is an essential part of human flourishing. Families and professionals struggle with any thought of withdrawing clinically assisted hydration and nutrition up to and including the last hours or days of life. When nutrition and hydration become clinically assisted they are classed as a treatment rather than basic care. Therefore, when they cease to offer overall benefit, they can be withdrawn. ${ }^{6,7}$

Recent systematic reviews highlight the lack of robust evidence to support

\section{Key Points}

Doctors are required to develop the skills to manage end-of-life decision making

Choice, though a popular approach, should be distinguished from autonomous decision making

Truth telling and effective communication skills are central to respecting a patient's autonomy

Decisions should be applied only to that individual. There is no place for a blanket approach or for tradition to replace clinical decision making

The use of opioids and sedatives in end-of-life care should rarely require the justification of the doctrine of double effect. Any doctor feeling the need to employ this doctrine to justify their action should contact specialist palliative care services for advice

KEY WORDS: cardiopulmonary resuscitation, doctrine of double effect, end of life, ethical decision making, withholding and withdrawing treatment

decision making in these areas. ${ }^{8,9}$ Traditional thinking in palliative care has held that the harms from providing clinically assisted hydration and nutrition in the last days or hours of life outweigh any benefits. The patient is not dying from a lack of hydration, but is dying and so does not require it. $^{10,11}$

\section{Cardiopulmonary resuscitation}

Attempts at cardiopulmonary resuscitation (CPR) are unlikely to be successful in restarting the heart as patients approach the end of their lives or, if they are, may result in a short period of significantly impaired quality of life. ${ }^{12,13}$ Agreement should be reached among the multidisciplinary team that this is the situation and a decision carefully recorded. ${ }^{14}$

Morally, there are few arguments that favour attempting CPR in the last days or weeks of life. There are significantly more practical challenges, especially with regard to the unrealistic expectations of both public and professionals.

Table 2. A layered approach to decision making when withholding or withdrawing treatment and interventions.

\begin{tabular}{|c|c|c|}
\hline Layer & Consideration & Issues \\
\hline 1 & The framework of facts: what we are bound by & $\begin{array}{l}\text { - The law } \\
\text { - Professional guidance } \\
\text { - Evidence base } \\
\text { - Resources available }\end{array}$ \\
\hline 2 & The patient & $\begin{array}{l}\text { - Their capacity } \\
\text { - Their beliefs and preferences } \\
\text { - Prognosis/outlook/likely changes in condition } \\
\text { - Other nominated decision makers where appropriate }\end{array}$ \\
\hline 3 & Formulate the ethical dilemma & $\begin{array}{l}\text { - Ensure the correct question(s) is being asked } \\
\text { - Are we being influenced by our own perspective? }\end{array}$ \\
\hline 4 & Establish the options & $\begin{array}{l}\text { - What are the potential moral justifications? } \\
\text { - What are the practical solutions? } \\
\text { - What communication/negotiation/explanation is required? }\end{array}$ \\
\hline 5 & Communicating and coordinating & $\begin{array}{l}\text { - Communicating the options to those involved } \\
\text { - Coordinating and putting into action the decision making }\end{array}$ \\
\hline
\end{tabular}


When CPR is considered a futile intervention, to discuss it with the patient would appear only to bring unnecessary distress. Discussion is, however, required about the patient's understanding of their general situation and outlook. An explanation that they are now dying may make further discussion about CPR itself irrelevant. A chance to air fears or concerns and make plans for their death would seem far more useful discussions to have, but the needs of patients who want to know more detail should also be met. For patients dying at home it is likely that more explicit discussion of $\mathrm{CPR}$ is required for them and their relatives to ensure emergency services are not called inappropriately.

Decisions not to attempt CPR refer only to CPR and should not influence other areas of decision making. Each potential intervention may be considered on its own merit as part of advance care planning.

Table 3. Association for Palliative Medicine (APM) position on the doctrine of double effect in end-of-life care.

1 The APM is an organisation of over 1,000 specialist palliative care doctors working in hospices, hospitals and the community

2 The double effect (sometimes called a rule, principle or doctrine) states that:

The risk of a potential, known (foreseen), unintended consequence or side effect of treatment is justified only if all the following criteria are met:

- the intended effect is good in itself

- the clinician's intention is solely to produce the good effect

- the intervention is proportionate to the situation

- the good effect is not achieved through the bad effect

3 There is a misconception that morphine-related drugs and sedative drugs bring about death more quickly, that doctors both know this and in some way condone their use with the double effect

4 The APM refutes this claim. It knows of no credible research evidence to suggest that a patient's life is shortened either by opioids or sedatives when used in line with accepted palliative care practice

5 The APM believes that the doctrine of double effect is unnecessary to justify the use or dosing regimens necessary to manage pain or distress in all but the most exceptional circumstances

6 Professionals concerned that they are shortening life by use of these medications should contact their local specialist palliative care services

Table 4. Association for Palliative Medicine (APM) position on the use of sedation at the end of life.

1 The APM is an organisation of over 1,000 specialist palliative care doctors working in hospices, hospitals and the community

2 All medication used in palliative care, including sedative medication, is aimed at the relief of specific symptoms

3 Medication which is sedating in its effect should be used only if the symptom cannot be relieved with more specific interventions

4 Rarely, patients may experience distress when symptoms cannot be controlled even after exhaustive attempts with specific interventions. In these circumstances, some patients may require sedating medication to diminish awareness of their suffering

5 If medication is sedating in its effect, the dose should be monitored to ensure that it is the minimum required to relieve the patient's distress. Medication used in this way does not shorten life

6 Sedation in palliative care is thus sedation while the patient dies and is not sedating the patient to death

7 Morphine and related drugs are vital painkillers but are wholly unsuitable for use as sedation

\section{Double effect and the use of opioids and sedation}

Opioids and sedatives provide effective relief for the frequently distressing symptoms of pain, dyspnoea and agitation as the end of life approaches. The frequent misconception among professionals is that the life of the patient may be shortened by increasing doses of these drugs in line with accepted clinical practice - a belief often shared by patients and their families. The doctrine of double effect (DDE) provides justification for such a consequence, but raises concern that it may protect dangerous practice.

The DDE states that an action (such as an increase in opioid dose) that the professional foresees may shorten life - but does not intend to have that result - is justified provided that the intention is to benefit the patient and not shorten their life. In the classic interpretation, a patient is in pain, a higher dose of opioid is given to relieve that pain, but at the same time in the belief that this may shorten life. This traditional argument has come under increasing challenge (Tables 3 and 4). ${ }^{15-17}$ Opioids and sedatives when used in line with best practice rarely require such high doses as to risk shortening life.

Consider also the DDE applied to other medications. Palliative chemotherapy or insulin can cause death, especially when given in doses outside those of recommended practice. If a patient died in these circumstances, there would be no protection under the DDE.

Any professional feeling that they may be shortening a patient's life by the use of opioids or sedatives should contact specialist palliative care services for advice.

\section{Documentation at the end of life}

\section{Integrated care pathways for the dying patient}

Integrated care pathways, such as the Liverpool Care Pathway for the dying patient, offer a method of documenting care given to patients in the last days or hours of life. Concern has been raised that use of the pathway may affect the outcome for patients. The pathway does 
not remove clinical judgement for what action is in the patient's best interests. It therefore does not influence outcomes provided that it is used appropriately. It provides a framework for the best care for patients at this stage of life and, as such, there is a moral responsibility to use it or equivalent guidance.

\section{Summary}

The doctor has a responsibility to develop and maintain an effective approach to ethical decision making and the skills to implement the correct moral action. At the heart of this process is the experience and knowledge of particular conditions and their outcomes, alongside excellence in communication skills and working with colleagues.

\section{Further information}

The General Medical Council released guidance on treatment and care towards the end of life in May 2010. Issues discussed in this article are covered by the guidance.

\section{References}

1 Department for Constitutional Affairs. Code of Practice Mental Capacity Act. London: DCA, 2005.
2 Murtagh FE, Thorns A. Evaluation and ethical review of a tool to explore patient preferences for information and involvement in decision making. J Med Ethics 2006;32:311-5.

3 Hancock K, Clayton JM, Parker SM et al. Truth-telling in discussing prognosis in advanced life-limiting illnesses: a systematic review. Palliat Med 2007;21:507-17.

4 Downie R, Randall F. Choice and responsibility in the NHS. Clin Med 2008;8:182-5.

5 Seale C. End-of-life decisions in the UK involving medical practitioners. Palliat Med 2009;23:198-204.

6 British Medical Association. Withholding and withdrawing life-prolonging medical treatment, 3rd edn. London: BMA, 2007.

7 General Medical Council. Withholding and withdrawing life-prolonging treatments: good practice in decision-making. London: GMC, 2002.

8 Good P, Cavenagh J, Mather M, Ravenscroft P. Medically assisted hydration for adult palliative care patients. Cochrane Database Syst Rev 2008; (2):CD006273.

9 Good P, Cavenagh J, Mather M, Ravenscroft P. Medically assisted nutrition for palliative care in adult patients. Cochrane Database Syst Rev 2008;(4):CD006274.

10 Campbell C, Partridge R. Artificial nutrition and hydration-guidance in end of life care for adults. London: National Council for Palliative Care and Association for Palliative Medicine, May 2007.

11 Lennard-Jones JE. Giving or withholding fluid and nutrients: ethical and legal aspects. J R Coll Physicians Lond 1999;33:39-45.
12 Sandroni C, Nolan J, Cavallaro F, Antonelli M. In-hospital cardiac arrest: incidence, prognosis and possible measures to improve survival. Intensive Care Med 2007;33:237-45.

13 Nolan JP, Laver SR, Welch CA et al. Outcome following admission to UK intensive care units after cardiac arrest: a secondary analysis of the ICNARC Case Mix Programme Database. Anaesthesia 2007;62:1207-16.

14 British Medical Association, Resuscitation Council (UK), Royal College of Nursing. Decisions relating to cardiopulmonary resuscitation. A joint statement from the British Medical Association, the Resuscitation Council (UK) and the Royal College of Nursing. London: BMA, 2007.

15 Estfan B, Mahmoud F, Shaheen P et al. Respiratory function during parenteral opioid titration for cancer pain. Palliat Med 2007;21:81-6.

16 George R, Regnard C. Lethal opioids or dangerous prescribers. Palliat Med 2007;21:77-80.

17 Sykes NP, Thorns A. The use of opioids and sedatives at the end of life in palliative care. Lancet Oncol 2003;4:312-8.

Address for correspondence:

Dr A Thorns, Pilgrims Hospice, University of Kent, Ramsgate Road, Margate, Kent CT9 4AD

Email: andrew_thorns@

pilgrimshospice.org 